Supporting Information:

\title{
Two-Dimensional Gold Sulfide Monolayers with Direct Band Gap and Ultrahigh
}

\section{Electron Mobility}

Qisheng $\mathrm{Wu},{ }^{\dagger, \downarrow, \Delta, \uparrow} \mathrm{Wen} \mathrm{Wu} \mathrm{Xu},{ }^{\S, \downarrow, \Delta}$ Dongdong Lin,,${ }^{\S}$ Jinlan Wang, ${ }^{\dagger}, *$ and Xiao Cheng Zeng ${ }^{\ddagger, *}$

${ }^{\dagger}$ School of Physics, Southeast University, Nanjing 211189, P. R. China

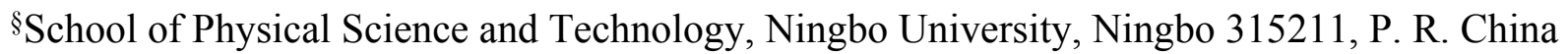

Department of Chemistry, University of Nebraska-Lincoln, Lincoln, Nebraska 68588, United States

*Correspondence should be addressed to: J.Wang (jlwang@seu.edu.cn) or X. C. Zeng (xzeng1@unl.edu)

TCurrent address: Department of Chemistry and Chemical Biology, University of New Mexico, Albuquerque, New Mexico 87106, United States 
Table S1. Lattice constants for $\mathrm{Au}_{2} \mathrm{~S}$ and $\mathrm{AuS}$ monolayers with or without DFT-D3 scheme included. It is clearly seen that DFT-D3 scheme has strong effects on the lattice structures. Although the gold sulfide monolayers are not layered structures, long distance dispersions cannot be ignored particularly in loose structures like $\gamma$-AuS.

\begin{tabular}{|c|c|c|c|c|c|}
\hline 2D system & $\alpha-\mathrm{Au}_{2} \mathrm{~S}$ & $\beta-\mathrm{Au}_{2} \mathrm{~S}$ & $\alpha$-AuS & $\beta$-AuS & $\gamma$-AuS \\
\hline $\begin{array}{c}\text { Lattice constants } \\
\text { with DFT-D3 }\end{array}$ & $a=b=5.74 \AA$ & $a=b=7.92 \AA$ & $\begin{array}{l}a=3.54 \AA \\
b=6.18 \AA\end{array}$ & $\begin{array}{l}a=6.08 \AA \\
b=6.68 \AA\end{array}$ & $\begin{array}{l}a=8.18 \AA \\
b=7.16 \AA\end{array}$ \\
\hline $\begin{array}{l}\text { Lattice constants } \\
\text { without DFT-D3 }\end{array}$ & $a=b=5.78 \AA$ & $a=b=8.00 \AA$ & $\begin{array}{l}a=3.54 \AA \\
b=6.26 \AA\end{array}$ & $\begin{array}{l}a=6.18 \AA \\
b=6.91 \AA\end{array}$ & $\begin{array}{l}a=8.77 \AA \\
b=6.65 \AA\end{array}$ \\
\hline
\end{tabular}

Table S2. Lattice parameters and atomic fractional positions for $\mathrm{Au}_{2} \mathrm{~S}$ and $\mathrm{AuS}$ monolayers.

\begin{tabular}{|c|c|c|}
\hline System & Lattice parameters & Fractional coordinates \\
\hline$\alpha-\mathrm{Au}_{2} \mathrm{~S}$ & $\begin{array}{c}a=b=5.74 \AA \\
c=20.0 \AA, \theta=90^{\circ}\end{array}$ & $\begin{array}{r}\text { Au1 }(0.250,0.750,0.453), \text { Au2 }(0.250,0.250,0.408), \\
\text { Au3 }(0.750,0.750,0.408), \text { Au4 }(0.750,0.250,0.408), \\
\text { S1 }(0.500,0.000,0.473), S 2(0.000,0.500,0.342)\end{array}$ \\
\hline$\beta-\mathrm{Au}_{2} \mathrm{~S}$ & $\begin{array}{c}a=b=7.92 \AA \\
c=20.0 \AA, \theta=90^{\circ}\end{array}$ & $\begin{array}{l}\text { Au1 }(0.002,0.243,0.528), \text { Au2 }(0.990,0.743,0.403), \\
\text { Au3 }(0.246,0.999,0.403), \operatorname{Au} 4(0.746,0.987,0.528), \\
\text { Au5 }(0.490,0.243,0.528) \text {, Au6 }(0.502,0.743,0.403), \\
\text { Au7 }(0.746,0.499,0.528), \text { Au8 }(0.246,0.487,0.403), \\
\text { S1 }(0.246,0.743,0.338), S 2(0.746,0.243,0.593), \\
\text { S3 }(0.746,0.743,0.466), \text { S4 }(0.246,0.243,0.466)\end{array}$ \\
\hline$\alpha$-AuS & $\begin{array}{c}a=3.54 \AA, b=6.18 \AA \\
c=20.0 \AA, \theta=90^{\circ}\end{array}$ & $\begin{array}{l}\text { Au1 }(0.500,0.500,0.359), \text { Au2 }(0.000,0.000,0.359) \\
\text { S1 }(0.500,0.822,0.301), \text { S2 }(0.500,0.179,0.418)\end{array}$ \\
\hline$\beta$-AuS & $\begin{array}{c}a=6.08 \AA, b=6.68 \AA \\
c=20.0 \AA, \theta=90^{\circ}\end{array}$ & $\begin{array}{l}\text { Au1 }(0.250,0.250,0.477), \text { Au2 }(0.750,0.750,0.477), \\
\text { Au3 }(0.750,0.250,0.477), \text { Au4 }(0.250,0.750,0.477), \\
\text { S1 }(0.320,0.500,0.399), \text { S2 }(0.680,0.500,0.399), \\
\text { S3 }(0.820,0.000,0.555), S 4(0.180,0.000,0.555)\end{array}$ \\
\hline$\gamma$-AuS & $\begin{array}{c}a=8.18 \AA, b=7.16 \AA \\
c=20.0 \AA, \theta=90^{\circ}\end{array}$ & $\begin{array}{c}\text { Au1 }(0.249,0.250,0.385), \text { Au2 }(0.249,0.750,0.385) \\
\text { Au3 }(0.749,0.750,0.385), \text { Au4 }(0.749,0.250,0.385) \\
\text { S1 }(0.402,0.000,0.422), \text { S2 }(0.096,0.500,0.348), \\
\text { S3 }(0.902,0.500,0.422), S 4(0.595,0.000,0.348)\end{array}$ \\
\hline
\end{tabular}


(a) $\alpha-A u_{2} S$

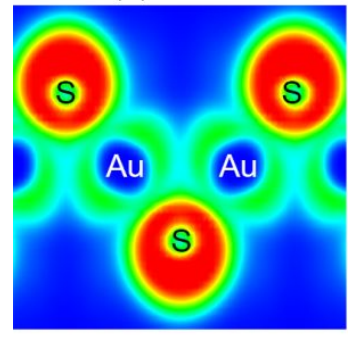

(c) a-AuS
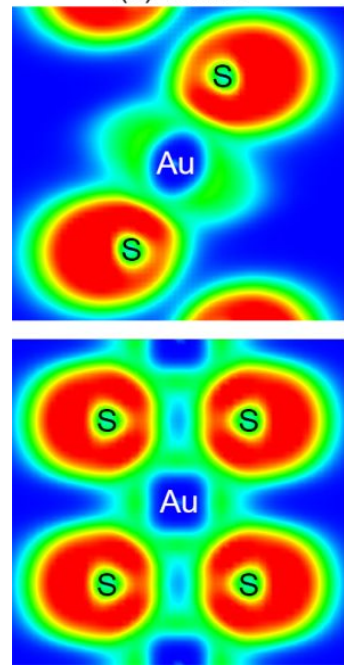

(b) $\beta-u_{2} S$

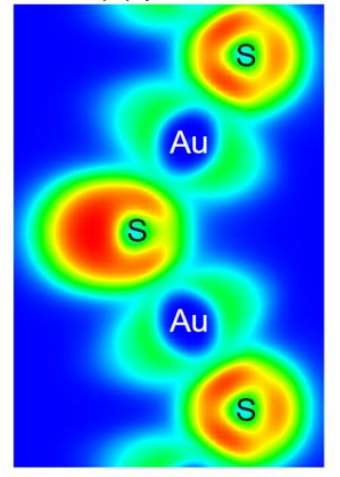

(d) $\beta$-AuS

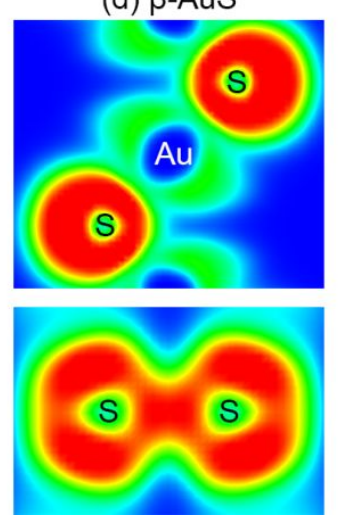

(e) y-AuS
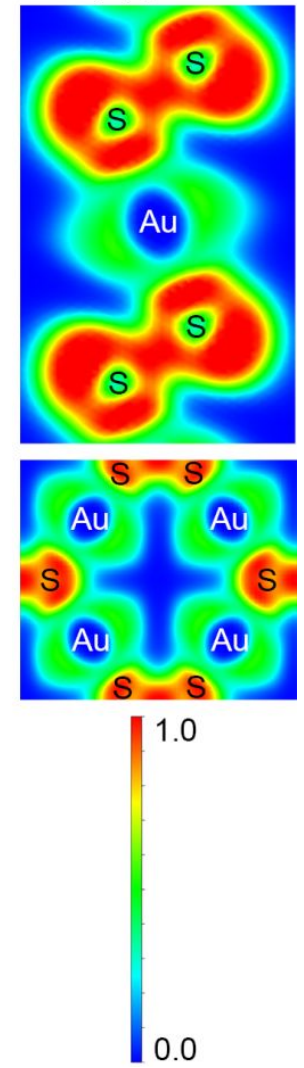

Figure S1. Electron localization functions (ELF) for $\mathrm{Au}_{2} \mathrm{~S}$ and $\mathrm{AuS}$ monolayers. 

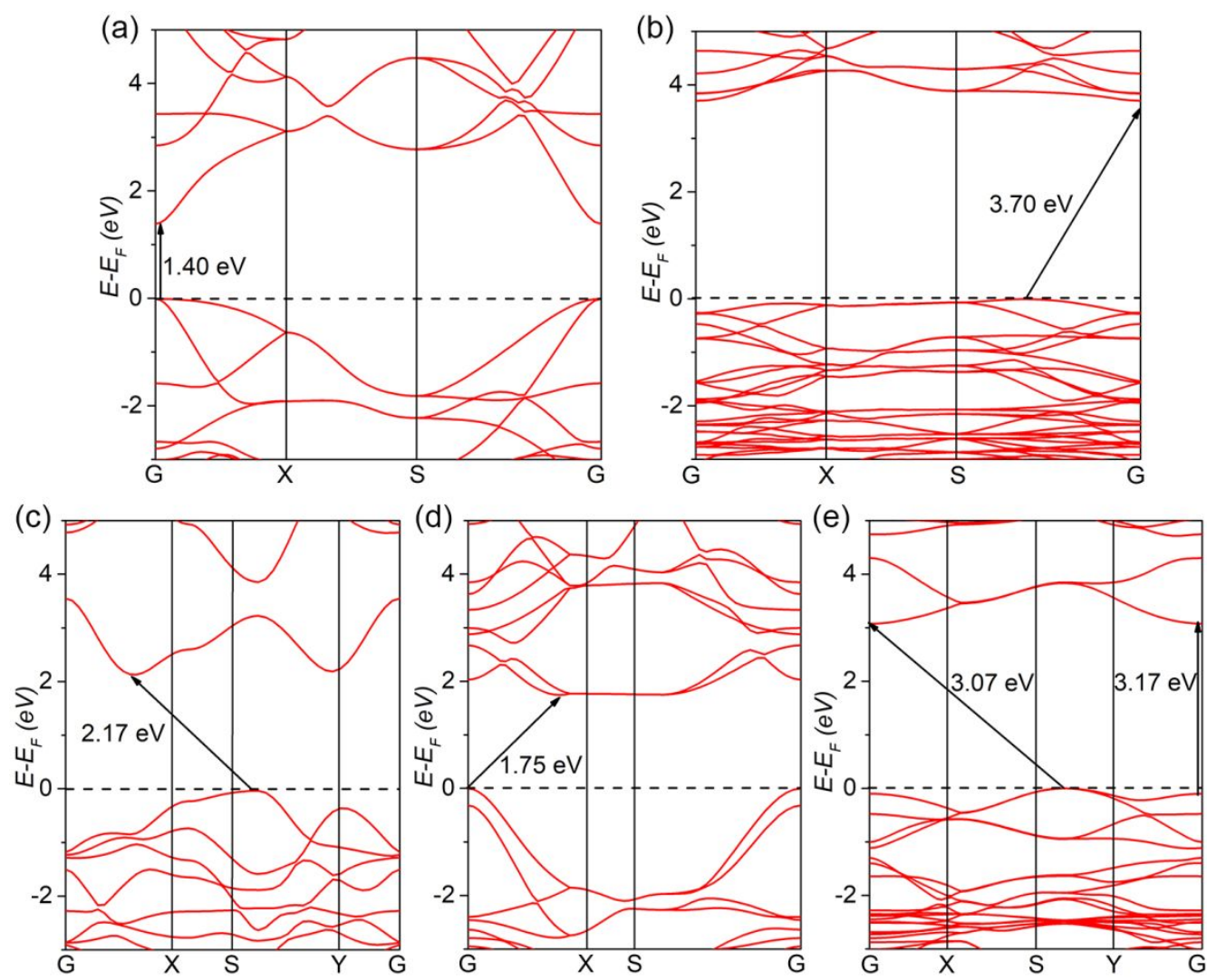

Figure S2. Band structures calculated by HSE06 functional without including spin-orbital coupling (SOC) effects for (a) $\alpha-\mathrm{Au}_{2} \mathrm{~S}$, (b) $\beta-\mathrm{Au}_{2} \mathrm{~S}$, (c) $\alpha$-AuS, (d) $\beta$-AuS and (e) $\gamma$-AuS monolayers. It is clearly seen that, to some degree, $\mathrm{SOC}$ reduces the band gaps of the $\mathrm{Au}_{2} \mathrm{~S}$ and $\mathrm{AuS}$ monolayers, as existing in many other 2D materials with heavy atoms. ${ }^{1}$ 

(a) $\quad \alpha-\mathrm{Au}_{2} \mathrm{~S}$
(b) $\quad \beta-\mathrm{Au}_{2} \mathrm{~S}$
(c) $\quad \alpha$-AuS
(d) $\beta$-AuS
(e) $\quad y$-AuS
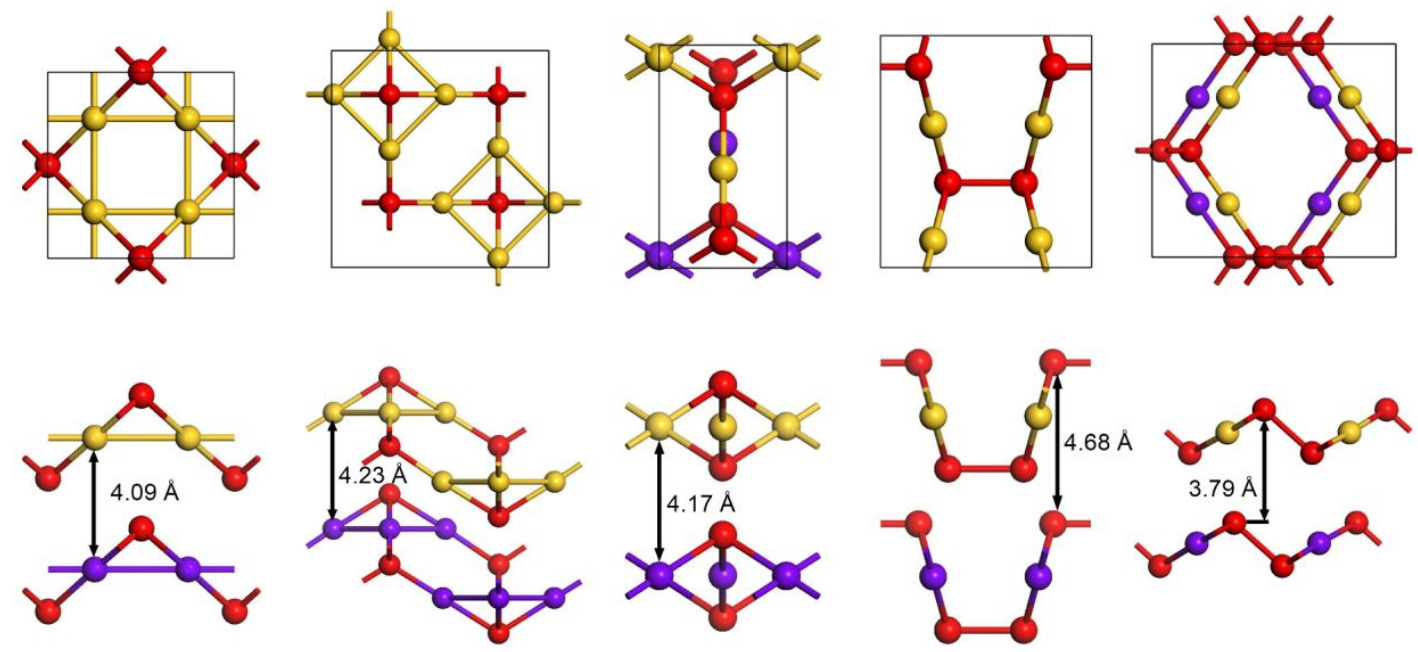

Figure S3. Atomic geometries (top and side views) of bilayer systems for $2 \mathrm{D} \mathrm{Au}_{2} \mathrm{~S}$ and $\mathrm{AuS}$ structures with their layer distances indicated. Gold and violet atoms denote $\mathrm{Au}$ atoms in two layers, respectively. Red atoms stand for $\mathrm{S}$ atoms.
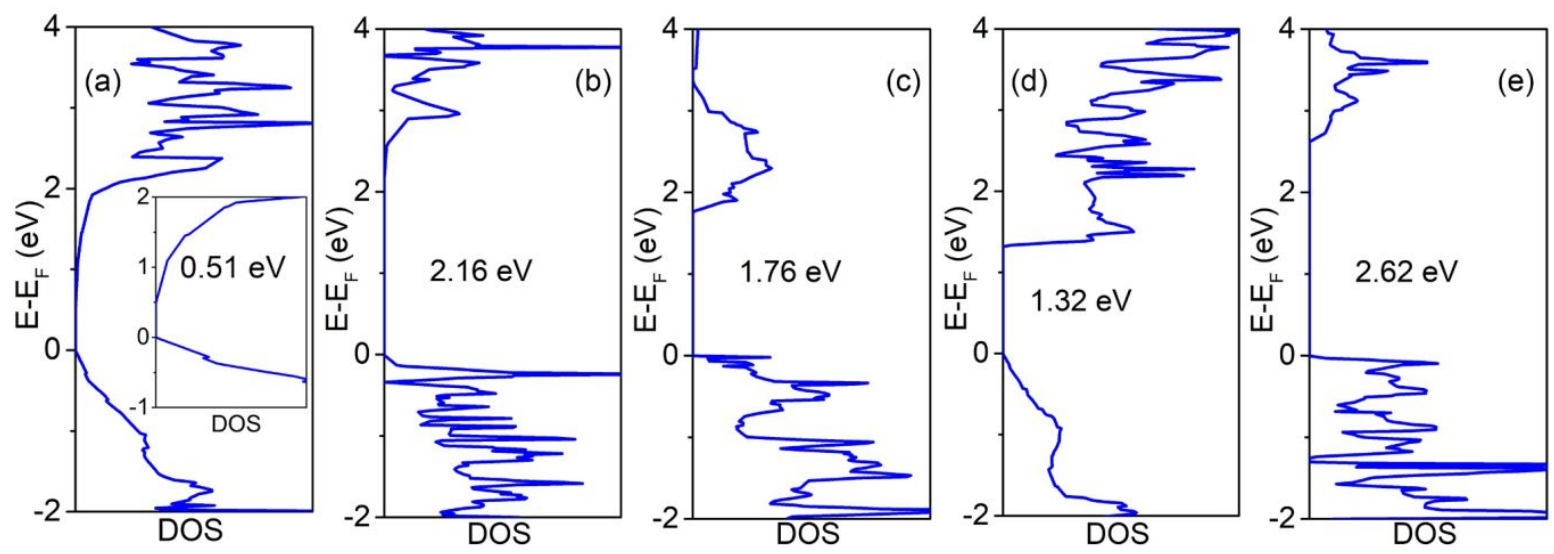

Figure S4. Density of states (DOS) of bilayer systems for $2 \mathrm{D}$ (a) $\alpha-\mathrm{Au}_{2} \mathrm{~S}$, (b) $\beta-\mathrm{Au}_{2} \mathrm{~S}$, (c) $\alpha-\mathrm{AuS}$, (d) $\beta$-AuS and (e) $\gamma$-AuS structures calculated on basis of HSE06 functional with SOC effects included. 

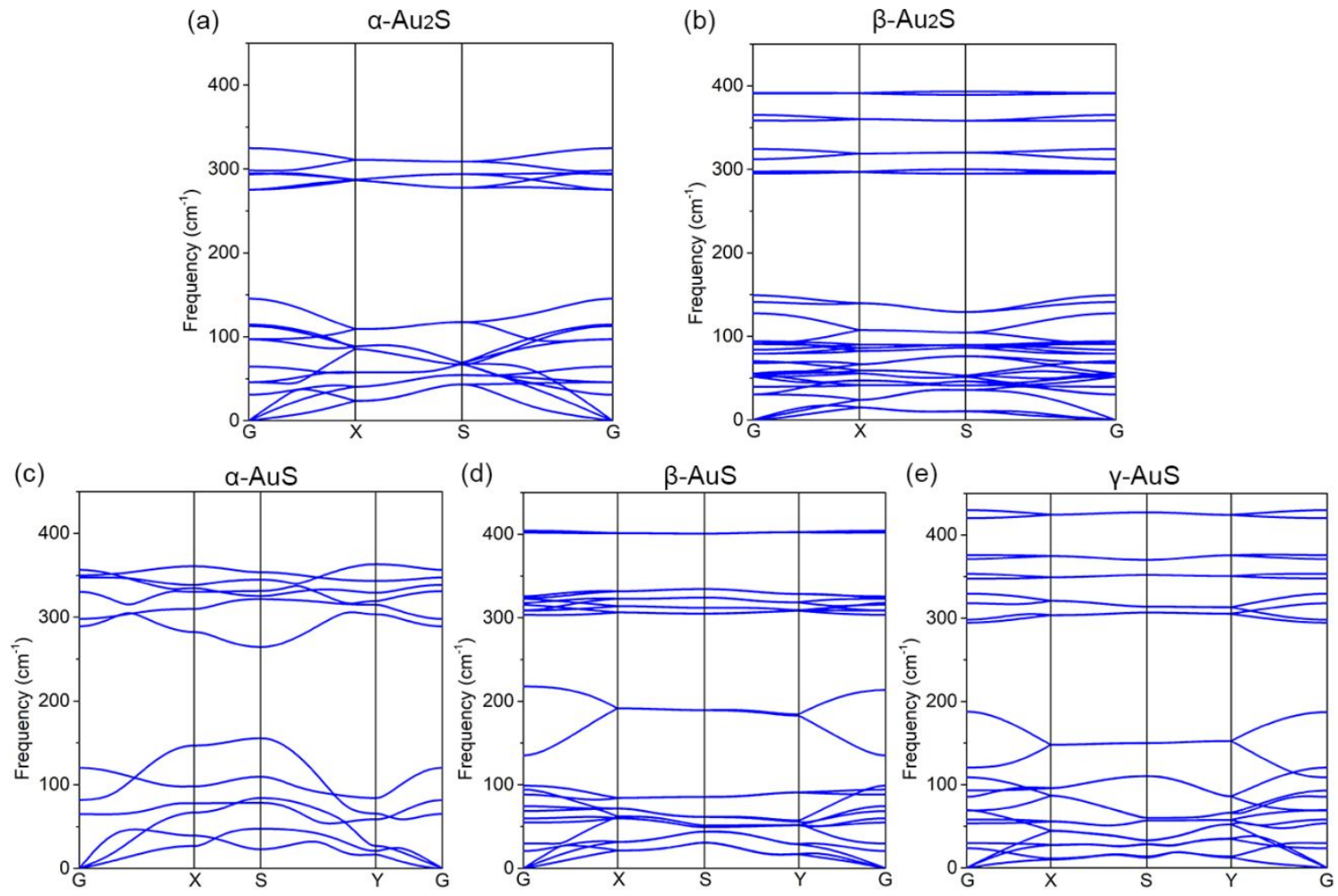

Figure S5. Phonon spectrums for $\alpha-\mathrm{Au}_{2} \mathrm{~S}$ (a), $\beta$ - $\mathrm{Au}_{2} \mathrm{~S}$ (b), $\alpha$-AuS (c), $\beta$-AuS (d) and $\gamma$-AuS (e) monolayers. 


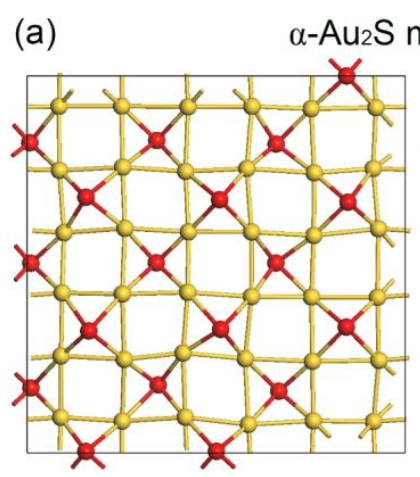

300 K, 5 ps

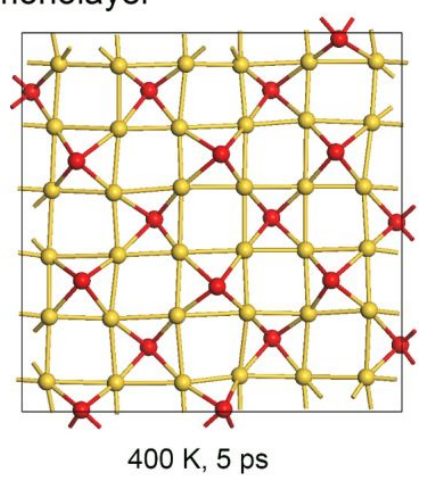

$400 \mathrm{~K}, 5$ ps

(b)

$\beta-\mathrm{Au}_{2} \mathrm{~S}$ monolayer
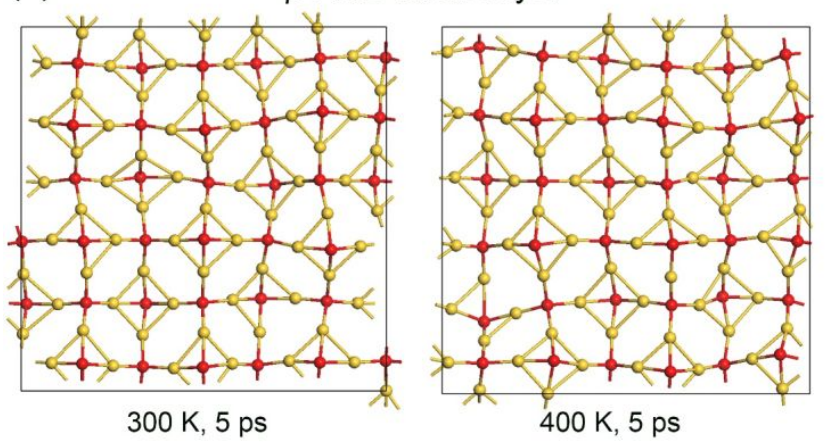

Figure S6. Ab initio molecular dynamics (AIMD) snapshots of $\mathrm{Au}_{2} \mathrm{~S}$ monolayers after annealing at $300 \mathrm{~K}$ and $400 \mathrm{~K}$ for $5 \mathrm{ps}$, respectively. 
(a)

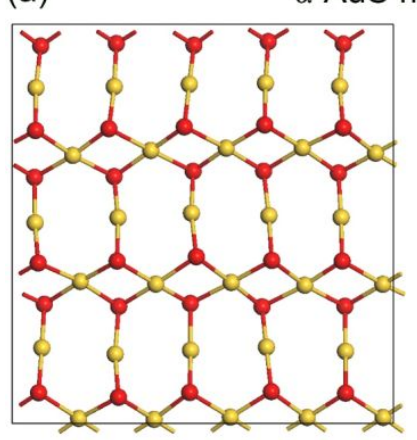

300 K, 5 ps

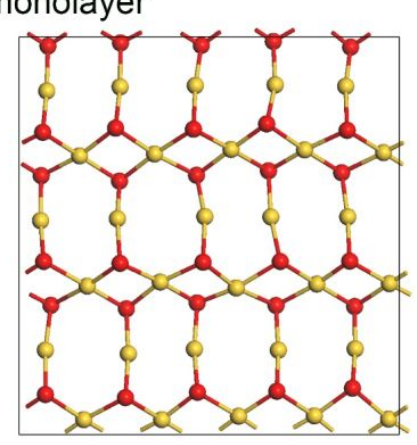

$400 \mathrm{~K}, 5$ ps

(b)

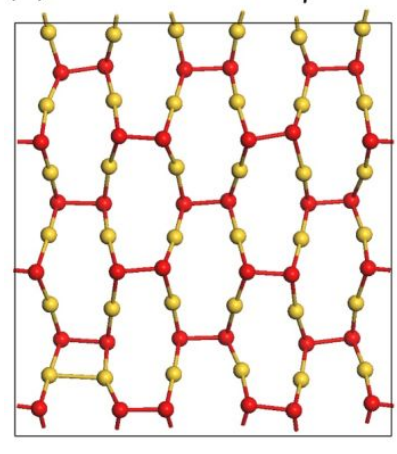

$300 \mathrm{~K}, 5 \mathrm{ps}$

$\beta$-AuS monolayer

(c)

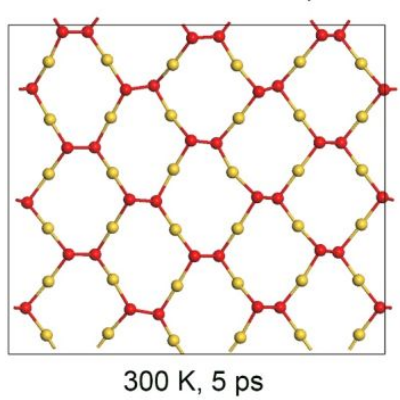

$\gamma$-AuS monolayer
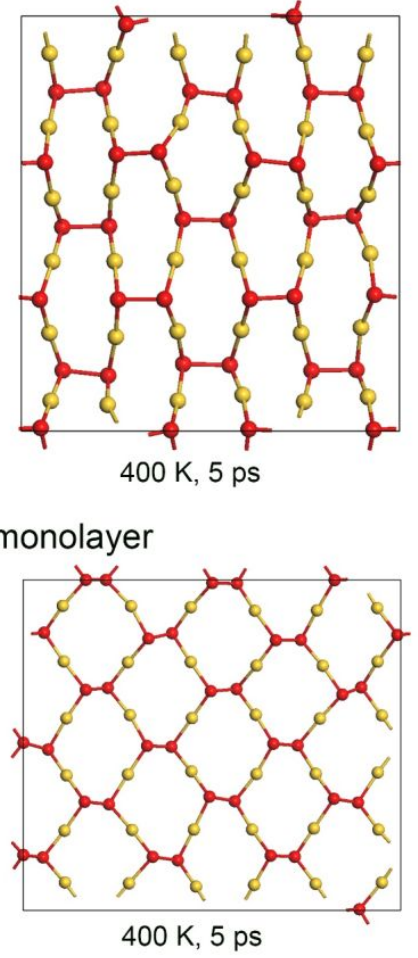

Figure S7. Ab initio molecular dynamics (AIMD) snapshots of AuS monolayers after annealing at $300 \mathrm{~K}$ and $400 \mathrm{~K}$ for $5 \mathrm{ps}$, respectively. 
(a)
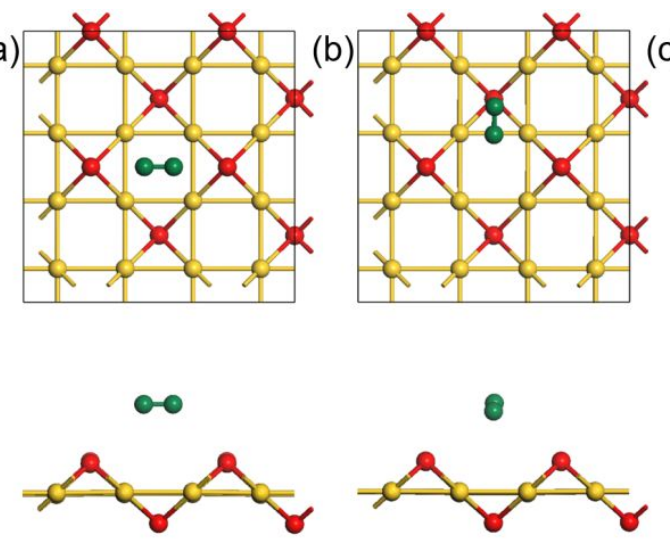

$6 \mathrm{meV}$

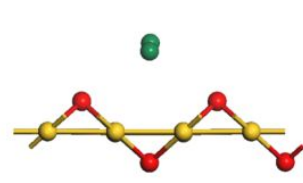

$-3 \mathrm{meV}$
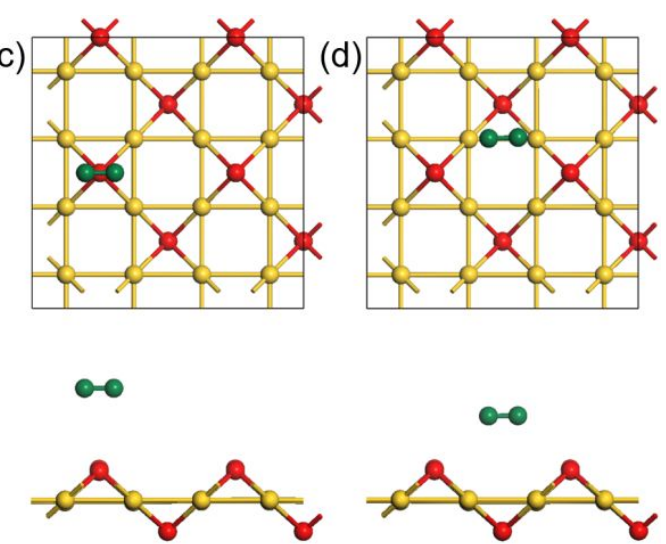

$11 \mathrm{meV}$

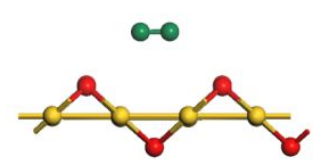

$3 \mathrm{meV}$

Figure S8. Top and side views for geometric structures of $\mathrm{O}_{2}$ molecule adsorbed on $\alpha-\mathrm{Au}_{2} \mathrm{~S}$ monolayer with adsorption energies indicated. The adsorption energies are defined as: $E_{a d s}=E_{\text {total }}-E_{O_{2}}-E_{\alpha-A u_{2} S}$, where the $E_{\text {total }}, E_{O_{2}}$ and $E_{\alpha-A u_{2} S}$ refer to energies of the system, $\mathrm{O}_{2}$ molecule and the $\alpha-\mathrm{Au}_{2} \mathrm{~S}$ monolayer, respectively. Negative values indicate that it is favorable for $\mathrm{O}_{2}$ molecule to adsorb on $\alpha-\mathrm{Au}_{2} \mathrm{~S}$ monolayer. The most stable geometry (b) is chosen for CI-NEB calculation. Gold, red and green spheres denote $\mathrm{Au}, \mathrm{S}$ and $\mathrm{O}$ atoms, respectively.
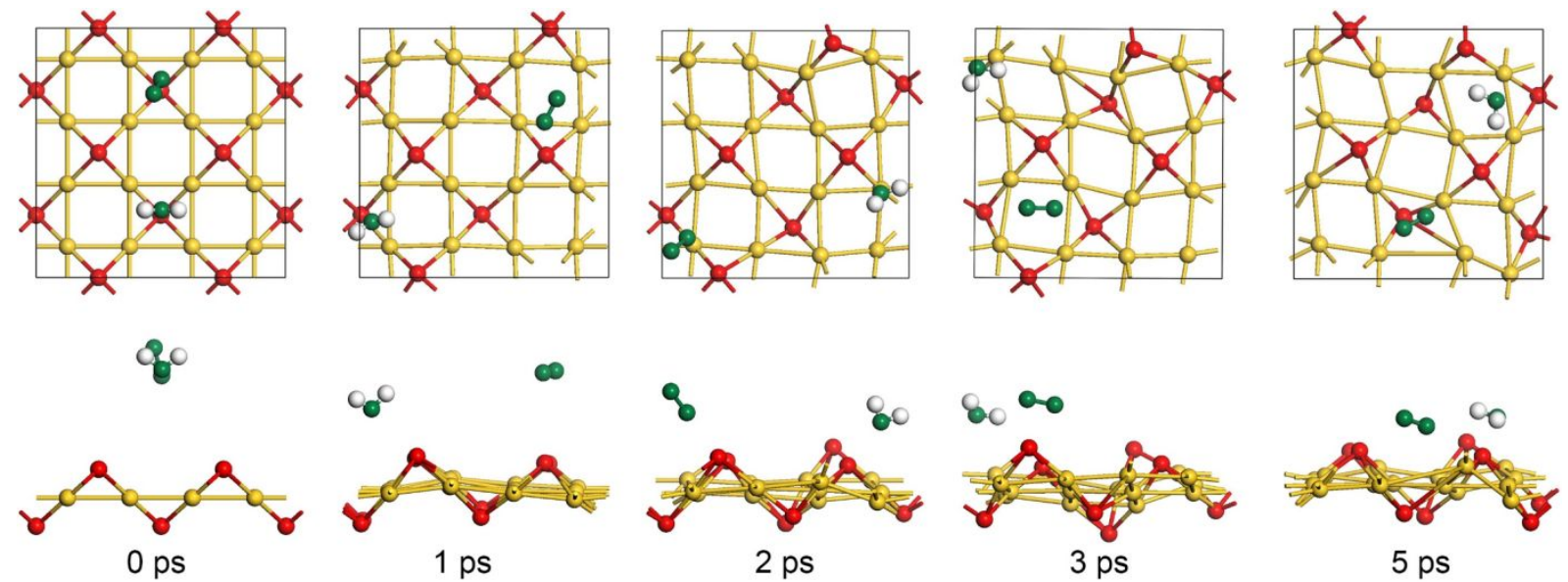

Figure S9. Snapshots of the simulated oxidation taken at $0 \mathrm{ps}, 1 \mathrm{ps}, 2 \mathrm{ps}, 3 \mathrm{ps}$ and $5 \mathrm{ps}$ for AIMD simulations of the $\alpha-\mathrm{Au}_{2} \mathrm{~S}$ monolayer with one $\mathrm{O}_{2}$ and one $\mathrm{H}_{2} \mathrm{O}$ molecule adsorbed. Gold, red, green and white spheres denote $\mathrm{Au}, \mathrm{S}, \mathrm{O}$ and $\mathrm{H}$ atoms, respectively.

\section{References:}

(1) Ma, L.; Dai, J.; Zeng, X. C. Two-Dimensional Single-Layer Organic-Inorganic Hybrid Perovskite Semiconductors. Adv. Energy Mater. 2017, 7, 1601731. 